\title{
Etanercept therapy in JIA: impact on the need for intra-articular steroid injections
}

\section{CE Pain*, AG Cleary and Heath Jill}

\author{
Address: Royal Liverpool Children's Hospital, Liverpool, UK
}

* Corresponding author

\author{
from $15^{\text {th }}$ Paediatric Rheumatology European Society (PreS) Congress \\ London, UK. 14-17 September 2008 \\ Published: 15 September 2008 \\ Pediatric Rheumatology 2008, 6(Suppl I):P68 doi:I0.I I86/I546-0096-6-SI-P68
}

This abstract is available from: http://www.ped-rheum.com/content/6/SI/P68

(c) 2008 Pain et al; licensee BioMed Central Ltd.

\section{Background}

In the UK etanercept is licensed for use in children with JIA age 4-17 years with active polyarticular disease which has not fully responded to or the child has been intolerant to methotrexate [1]. Studies have shown that the annual cost of treatment with the addition of etanercept is only slightly higher than prior costs because of reduced inpatient and outpatient visits, reduction in need for other treatments and reduction in loss of parental earnings [2]. The aim of this pilot study is to confirm that the cost of etanercept in a UK cohort is off-set by the reduction in intra-articular steroid injections.

\section{Materials and methods}

A pilot study was undertaken by random selection of 18 cases from the local etanercept database. The following information was obtained by case note analysis: age, sex, ILAR classification and joint injection episodes for 12 months pre and post commencement of etanercept.

\section{Results}

The mean age at start date of etanercept was 9.3 years (range was 2.4 years to 16 years). 14 (78\%) were girls and $4(22 \%)$ were boys. The diagnosis was polyarticular $(\mathrm{n}=$ $7)$, extended oligoarticular $(n=8)$, persistent oligoarticu$\operatorname{lar}(\mathrm{n}=1)$, enthesitis related $(\mathrm{n}=1)$ and unclassified $(\mathrm{n}=$ $1)$.

Pre etanercept there were 25 joint injection episodes in 15 patients and 9 episodes post-etanercept, representing a reduction of $64 \%$.

\section{Conclusion}

This pilot study showed a reduction in the need for intraarticular steroid injections post etanercept. We are extending this analysis to our entire cohort and calculating the cost implications.

\section{References}

I. NICE: Guidance on the use of etanercept for the treatment of juvenile idiopathic arthritis Volume 35. National Institute for Clinical Excellence (NICE) Clinical Guideline; 2002.

2. Haapasaari J, Kautiainen HJ, Isomäki HA, Hakala M: Etanercept does not essentially increase the total costs of the treatment of refractory juvenile idiopathic arthritis. J Rheumatol 2004, 3I:2286-2291. 